\title{
A Characterization and Evaluation of Antibacterial Efficacy of Bacteriocin Produced by Bacillus subtilis Isolated from Raw Milk
}

\author{
P. S. Sharmila ${ }^{1 *}$ and A. K. Vidya ${ }^{2}$ \\ Department of Biochemistry, Kongu Arts and Science College, Erode - 638107, Tamil Nadu, India; \\ sharmishanthi55@gmail.com, vidhya_ak@hotmail.com
}

\begin{abstract}
This study presents Bacteriocin (antimicrobial compound) produced from Bacillus subtilis isolated from unpasteurized milk. The antibiotic susceptibility tests for $B$. subtilis isolated from raw milk against various antibiotics demonstrated high sensitivity to Tetracycline, Moderate and less sensitivity towards Streptomycin and Chloramphenicol respectively while being resistant to Penicillin. Culture filtrate containing Bacteriocin showed thermostability (up to $100^{\circ} \mathrm{C}$ ), expressed a $\mathrm{pH}$ tolerance (2.0-10.0) and emerged resistance towards trypsin and pepsin. Partial purification of bacteriocin was performed using ammonium sulphate precipitation and then purified by passing into a column of Silica gel. In SDS-PAGE analysis, purified bacteriocin isolated from Bacillus subtilis showed the molecular weight to be approximately 3.4 KDa. The isolate Bacteriocin was tested finally for antibacterial activity against $E$. coli, associated with food borne illnesses. The zone of inhibition clearly proved that Bacteriocin has inhibitory effect on the food pathogen $E$. coli, thus confirming its bactericidal action in food.
\end{abstract}

Keywords: Antibacterial Agent, Bacteriocin, Bacteriocidal, Biopreservative, Bacillus subtilis, E. coli, Micrococcus luteus

\section{Introduction}

Majority of bacteria produce antimicrobial compounds such as broad spectrum classical antibiotics, metabolic products like organic acids and lytic agents such as lysozyme, besides several types of protein exotoxin and bacteriocins, that are biologically active compounds with bactericidal action. Bacteriocin (antimicrobial peptides) family is the most abundant and diverse group of bacterial defence systems. Bacteriocins are peptides produced by microbes that are usually active against bacteria closely similar to the producer organism [5]. Some bacteriocins are active against pathogenic and food spoilage bacteria and much research has focused on their potential as antimicrobials in food preservation. Contrary to the currently used antibiotics, bacteriocins are generally recognized to be more natural and hence they are believed to have been present in many of foods eaten since ancient times [1].
Though a great deal of research work is carried out on the bacteriocins produced by lactic acid bacteria they have the disadvantage that they are unsuitable for use as probiotics in the agricultural industry since they are sensitive to heat and effect of salts.

Similar to LAB, some candidates of Bacillus species such as B. subtilis, B. lichniformis are Generally Considered as Safe (GRAS) bacteria [7]. Bacillus subtilis is well known to produce many antibiotic and antimicrobial compounds including the bacteriocins [8]. In particular, bacteriocins from Bacillus subtilis are found to exhibit antimicrobial activity against several pathogenic organisms like Micrococcus luteus and Escherichia coli. This distinctive property of Bacillus subtilis enhances its utilization as a probiotics and hence used up in bio preservation.

Therefore, in the present study, our primary objective was to evaluate the practical use and application of Bacillus bacteriocins in the preservation of food with an

${ }^{*}$ Author for correspondence 
attempt to isolate and characterise the bacteriocin from Bacillus subtilis that has been isolated from raw milk, to get a better insight into its bacteriocidal properties against food borne pathogen such as E. coli.

\section{Materials and Methods}

All chemicals used in the present investigation were procured from Himedia, Mumbai, India.

\subsection{Selective Isolation of Bacillus subtilis}

Samples from dairy products such as raw unpasteurized milk was processed for isolation of Bacillus subtilis. Spore forming Bacillus subtilis was identified by ethanol treatment and heat treatment. In ethanol treatment, the sample was treated with ethanol for about 30 minutes where as in case of heat treatment, the sample was heated to $80^{\circ} \mathrm{C}$ for 20 minutes. The treated samples were then overlaid with the indicator strain, (Micrococcus luteus) to isolate spore forming bacteriocin producing Bacillus subtilis. The isolated colonies showing zone of inhibition were selected for further studies. The suspected colonies were Gram positive bacteria and identified as Bacillus subtilis as per Microbial tests (Gram staining, endospore staining), Biochemical tests (IMViC tests, Catalase test, Starch hydrolysis, Casein hydrolysis, Urease test, Nitrate reductase test, Lipid hydrolysis test, Fermentation test, Oxidase test) and Physiological Tests (Growth at different $\mathrm{pH}$ ).

\subsection{Antibiotic Assay}

Antibiotic assay was a modification of the agar overlay diffusion method. Cells were grown in LB broth at $37^{\circ} \mathrm{C}$ for $16 \mathrm{hrs}$. Previously prepared nutrient agar plates containing $15 \mathrm{ml}$ of nutrient agar were overlaid with $4 \mathrm{ml}$ of soft agar (1\%) loaded with $200 \mu$ of freshly grown cells. Antibiotic discs were prepared and dispended on to the solid media and incubated at $37^{\circ} \mathrm{C}$ under anaerobic conditions for 24 hours. Zone of inhibition were measured and susceptibility was observed.

\subsection{Testing of Culture Filtrate of Isolated Cultures for Antimicrobial Activity}

Agar well diffusion is performed to assay for the culture filtrate activity of the isolates against the indicator strain Micrococcus luteus [3]. To determine antimicrobial activity, the isolates grown overnight in LB broth by continuous shaking were taken. It was then centrifuged twice at $10,000 \mathrm{rpm}$ at $4{ }^{\circ} \mathrm{C}$ for 10 minutes. The culture filtrate was taken and tested its antimicrobial activity. The NA was poured onto petriplates and allowed to solidify. It was then overlaid with LB soft agar containing the indicator strain. Wells were then made with the help of gel puncture and about $50 \mu$ of culture filtrates were added to the well. The plates were then kept for incubation at $37^{\circ} \mathrm{C}$ for overnight. Appearance of zone around the well determines the antimicrobial property of the isolates.

\subsection{Thermostability and $\mathrm{pH}$ Optimization of the Culture Filtrate}

Thermostability and $\mathrm{pH}$ optimization was done to determine the ability of the cell free supernatant to exhibit antimicrobial compound at different temperatures and also at different $\mathrm{pH}$ range. For this purpose, the overnight grown culture was taken and the cells were deleted down by centrifuging at $10,000 \mathrm{rpm}$ for 10 minutes. The culture filtrate $\mathrm{pH}$ was adjusted to $\mathrm{pH}$ range of $2,4,6,8$, and 10 . Simultaneously the culture filtrate was also adjusted to heat treatment at varying temperature $\left(40^{\circ} \mathrm{C}, 60^{\circ} \mathrm{C}, 80^{\circ} \mathrm{C}\right.$, $100^{\circ} \mathrm{C}$ and $120^{\circ} \mathrm{C}$ ) and incubated at $37^{\circ} \mathrm{C}$ for 10 minutes. Subsequently the $\mathrm{pH}$ was neutralized and the activity of both $\mathrm{pH}$ and heat treated culture filtrate were checked by gel diffusion assay.

\subsection{Proteolytic Inactivation of Culture Filtrate}

To determine the effect of proteolytic enzyme on culture filtrate, culture was grown and centrifuged at 10,000rpm for 10minutes and the culture filtrate was collected. $10 \mu \mathrm{l}$ of enzyme stock solution was added to $20 \mu$ l of culture filtrate and incubated at $37^{\circ} \mathrm{C}$ for $6 \mathrm{hrs}$. NA plates overlaid with LB soft agar along with the indicator strain were prepared. The wells were made with the help of gel puncture and the enzyme treated Culture Filtrate was pipetted into the wells. The plates were then kept at $37^{\circ} \mathrm{C}$ and observed for zone of inhibition. If the enzyme treated samples show negative results compared to that of the positive control, it means the activity was due to protein, possibly bacteriocin.

\subsection{Extraction of Crude Bacteriocin Ammonium Sulphate Precipitation Method}

In this method, $50 \mathrm{ml}$ of LB broth was inoculated with the test culture and kept for overnight incubation. The culture broth was then transferred to sterile polypropylene 
tubes and centrifuged at 10,000rpm for 10 minutes at $4^{\circ} \mathrm{C}$. The cell free extract was collected by centrifugation and the supernatant was transferred into a beaker. The solution was stirred in magnetic stirrer using magnetic bead and ammonium sulphate (50\%) was added slowly till its final saturation. The proteinaceous bacteriocin tends to precipitate by the slow addition of ammonium sulphate. This was kept at $4^{\circ} \mathrm{C}$ for overnight. The solution was then centrifuged at 10,000rpm for 15 minutes. The supernatant was decanted and the pellet was resuspended in sterile distilled water.

\subsection{Purification by Column Chromatography}

For purification, 1.0 gm of Silica gel 100-200 Mesh was added to $50 \mathrm{ml}$ sterile distilled water and kept for overnight soaking. To this $10 \mathrm{ml}$ of crude bacteriocin sample was added onto the top of the gel and allowed to permeate into the gel by running the column. After 30 minutes the samples were eluted and the fractions were collected at 15 minutes interval each in 5 Eppendorf tubes and stored at $-20^{\circ} \mathrm{C}$.

\subsection{Characterisation of Crude Bacteriocin SDS-PAGE}

SDS PAGE was done to determine the molecular weight and purity of protein. SDS PAGE was carried out using $15 \%$ and $4 \%$ concentration of acrylamide. Protein fraction with highest concentration was pooled and loaded onto the well along with a pre stained broad range marker (3.5KD-7.8KD). Electrophoresis was carried out at constant current of 50mA until the tracking dye (mercaptoethanol) had migrated till the end. The gel was stained using the staining solution (Coomassie brilliant blue 250, methanol, acetic acid, distilled water) for 4 hours and destained overnight using destaining solution (methanol, acetic acid, distilled water) till protein bands were closely visible with low background.

\subsection{Protective Effect of Bacteriocin on E. coli}

Escherichia coli are a gram-positive, rod shaped bacterium that is commonly found in the lower intestine of warmblooded organisms. Most E. coli strains are harmless, but some serotypes are pathogenic and possibly cause severe food poisoning in humans.

It has been observed that $35 \%$ of food and $57.5 \%$ of water used by vendors were contaminated by $E$. coli and coli forms respectively [6]. Holding the food for longer time creates favourable conditions for the growth of foodborne pathogens. Hence, the counts of E. coli, Staphylococcus aureus, Bacillus cereus and Clostridium perfringens are reported to be high in such foods.

\section{Assessment of Antimicrobial Activity}

To perform the action, purified antimicrobial compound was taken and its activity was tested. The NA was poured on to petriplates and allowed to solidify. It was overlaid with LB soft agar seeded with the pathogenic strain namely E. coli. Wells were then made with a diameter of $6 \mathrm{~mm}$ and $30 \mu \mathrm{l}$ of antimicrobial compound were added to the well. The plates were then incubated at $37^{\circ} \mathrm{C}$ for overnight. Appearance of zone around the well determines the antimicrobial activity of the Bacteriocin on E. coli.

\section{Results and Discussion}

\subsection{Screening and Isolation of Bacteriocin Producing Bacillus Cultures from Various Sources}

Bacillus subtilis spore formers are commonly found in fermented food and soil. Cultures were isolated selectively by ethanol treatment and heat treatment from raw milk and curd. Colony producing bacteriocin exhibits zone of inhibition against the indicator organism, Micrococcus

Table 1. Zone of inhibition of the cultures

\begin{tabular}{|c|c|c|}
\hline S.No & $\mathbf{1}$ & $\mathbf{2}$ \\
\hline Isolates & Bacillus subtilis & Bacillus species \\
\hline Sources & Raw milk & Curd \\
\hline $\begin{array}{c}\text { Antimicrobial } \\
\text { activity }\end{array}$ & +++ & - \\
\hline
\end{tabular}

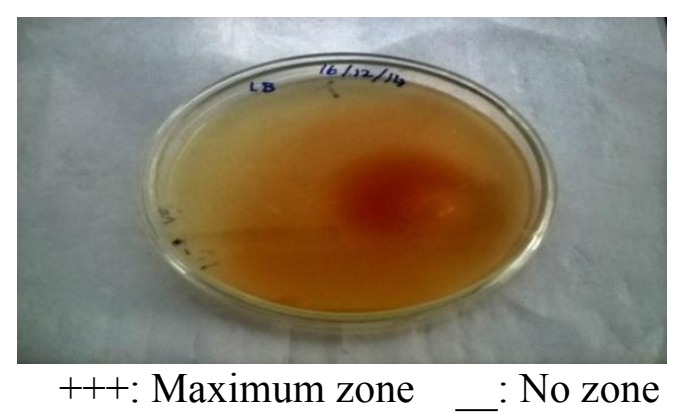

Plate 1. Isolated colonies showing zone of inhibition against the indicator organism Micrococcus luteus. 
luteus. The following table shows the zone produced by the cultures against the lawn of the indicator organism.

\subsection{Characterization of Bacteriocinogenic Bacillus subtilis}

\subsubsection{Microbial Characteristics of the Isolates}

The isolated culture was found to be Rod-shaped, Grampositive and Spore bacteria from morphological analysis.

\subsubsection{Identification of Culture by Biochemical Tests}

The culture was identified by biochemical tests.

\subsubsection{Identification of Physiological Properties}

The growth of the selected isolate was tested at different $\mathrm{pH}(2,4,6,7,8,10,12$ and 14).

It was obvious from the result that the isolate grow at a $\mathrm{pH}$ range of 4 to 12 and optimal growth achieved between pH 7 and 8.

\subsection{Antibiotic Susceptibility}

The selected isolates were tested for its susceptibility towards various antibiotics such as Streptomycin, Chloramphenicol, Penicillin.

Table 2. Biochemical properties of the Bacillus subtilis

\begin{tabular}{|c|c|}
\hline Biochemical Tests & Results \\
\hline Indole & - \\
\hline Methyl red & - \\
\hline Vogues proskaeur & + \\
\hline Citrate & + \\
\hline Catalase & + \\
\hline Starch hydrolysis & + \\
\hline Casein hydrolysis & + \\
\hline Urease & + \\
\hline Nitrate reduction & + \\
\hline Lipid hydrolysis & Yellow /Yellow without gas \\
\hline Triple Sugar Iron & production (acid slant/acid butt) \\
\hline Oxidase & - \\
\hline
\end{tabular}

+: Positive _: Negative

Yellow/yellow: Glucose and Lactose or Sucrose fermentation has occurred.
Table 3. Physiological properties of the isolates

\begin{tabular}{|c|c|c|c|c|c|c|c|c|c|}
\hline \multirow{2}{*}{ Properties } & \multirow{2}{*}{ Morphology } & \multicolumn{7}{|c|}{ Growth at different pH } \\
\cline { 2 - 9 } & 2 & 4 & 6 & 7 & 8 & 10 & 12 & 14 \\
\hline $\begin{array}{c}\text { Bacillus } \\
\text { subtilis }\end{array}$ & Rod & - & + & ++ & +++ & +++ & ++ & + & - \\
\hline
\end{tabular}

+++: Maximum growth ++: Minimum growth _: No growth

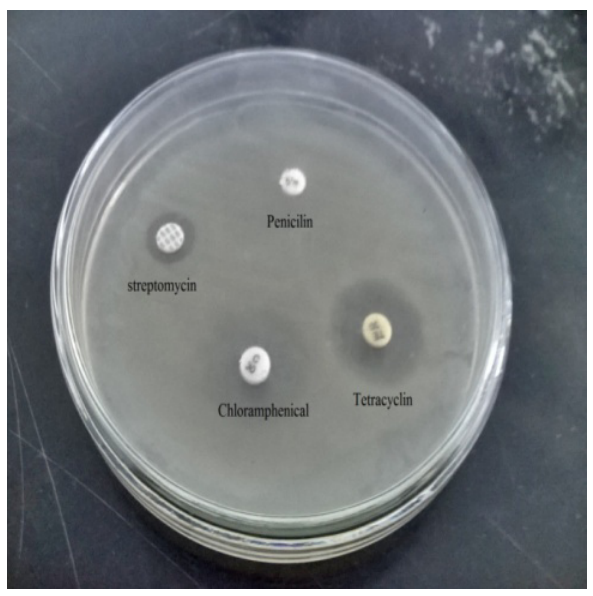

Plate 2. Antibiotic susceptibility of the culture, Bacillus subtilis towards various antibiotics.

Table 4

\begin{tabular}{|c|c|c|c|}
\hline Antibiotics & $\begin{array}{c}\text { Content } \\
(\mu \mathrm{g} / \mathrm{disc})\end{array}$ & $\begin{array}{c}\text { Growth- } \\
\text { inhibition } \\
\text { zone }(\mathrm{mm})\end{array}$ & Sensitivity \\
\hline Tetracycline & 30 & 19 & Strong \\
\hline Streptomycin & 30 & 08 & Moderate \\
\hline Chloramphenicol & 30 & 3 & Less \\
\hline Penicillin & 30 & 0 & None \\
\hline
\end{tabular}

The above results showed that the culture is highly sensitive to the antibiotic. Tetracycline. Moderate and less sensitive towards Streptomycin and Chloramphenicol respectively. No sensitivity is shown by Penicillin.

\subsection{Thermostability and $\mathrm{pH}$ of Culture Filtrate}

Antimicrobial protein production by culture filtrate was strongly dependent on $\mathrm{pH}$ and temperature. In our study, culture filtrate exhibited antimicrobial activity at acidic, neutral and basic pH levels (2-10), and the optimal activity was noticeable at $\mathrm{pH} 6.0$ and 6.5. Similar results were observed [4]. The activity of culture organism exhibiting antimicrobial activity observed at different growth 

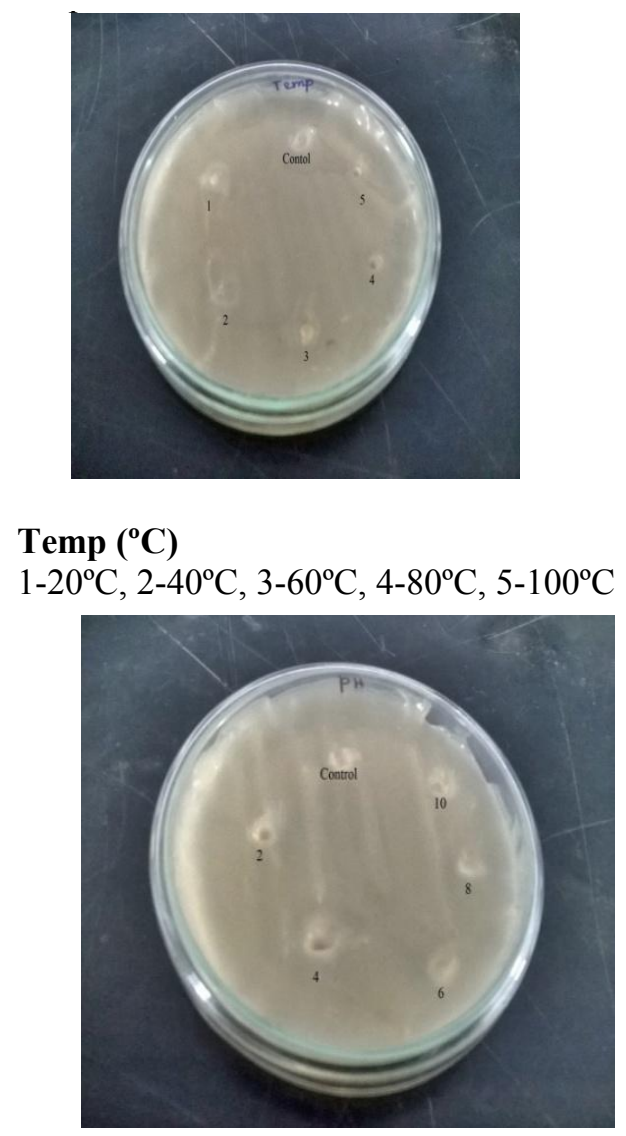

\section{Control (CF) pH}

Plate 3. Plates showing Thermostability and $\mathrm{pH}$ optimization of the culture filtrate

temperatures, suggested that the temperature play an important role in antimicrobial production.

\subsection{Sensitivity of the Culture Filtrate to Different Proteolytic Enzymes}

To study and check the nature of the antimicrobial compound and find out whether it is a protein or not, the cell free supernatant was treated with various proteolytic enzymes like pepsin, trypsin and its activity was checked against Micrococcus luteus.

Bacillus subtilis showed the resistance to trypsin and pepsin but it may be sensitivity to pronase $\mathrm{E}$ and protease $\mathrm{K}$.

\section{Purification by Column Chromatography}

This method was employed for purifying a compound. Hence the protein was completely eluted from the column.
That protein was utilized for protective action against E. coli. Antimicrobial compound was purified by silica gel-mesh 100 - 200 column chromatography. Purified compound was collected in 5 Eppendorf tubes at the interval of 15 minutes each and it was stored at $-20^{\circ} \mathrm{C}$.

\section{Characterization of Crude Bacteriocin by SDS-PAGE}

SDS-PAGE was done to determine the molecular weight of the desired compound.

The above result revealed the isolate Bacillus subtilis is found to have a molecular weight of approximately 3.4 $\mathrm{KDa}$. The Single protein band obtained upon staining with Coomassie brilliant blue clearly illustrate the purity of the protein.

\section{Protective effect of Bacteriocin on $E$. coli}

\subsection{Testing Culture Filtrate and Purified Bacteriocin against Pathogenic E. coli}

Agar well diffusion assay is performed to assay the antimicrobial activity against the pathogenic organism.

The zone of inhibition as shown in Plate 5 clearly prove that bacteriocin and culture filtrate are effective

Table 5. Proteolytic inactivation of culture filtrate byvarious enzymes

\begin{tabular}{|c|c|c|c|}
\hline S.No & Isolates & \multicolumn{2}{c|}{ Proteolytic enzymes } \\
\hline \multicolumn{2}{|c|}{} & Trypsin & Pepsin \\
\hline $\mathbf{1}$ & Bacillus subtilis & ++ & ++ \\
\hline
\end{tabular}

++: minimum activity +++: maximum activity

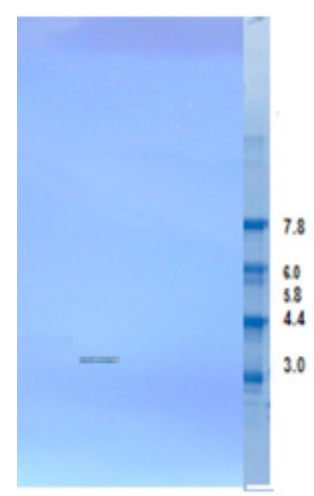

Plate 4. Molecular weight determination of the sample by SDS-PAGE 


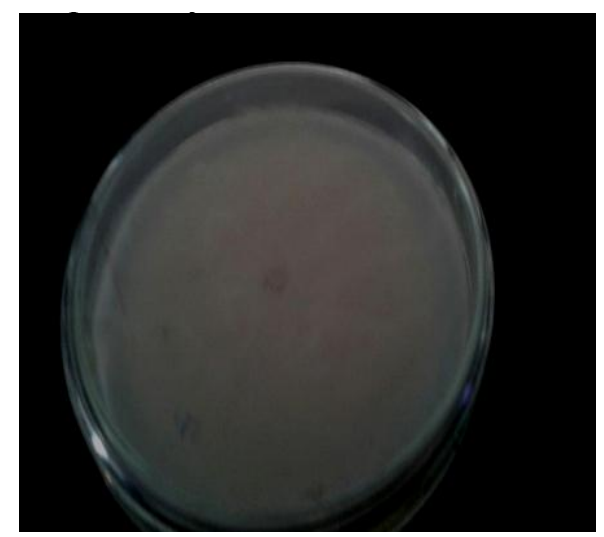

Purified bacteriocin

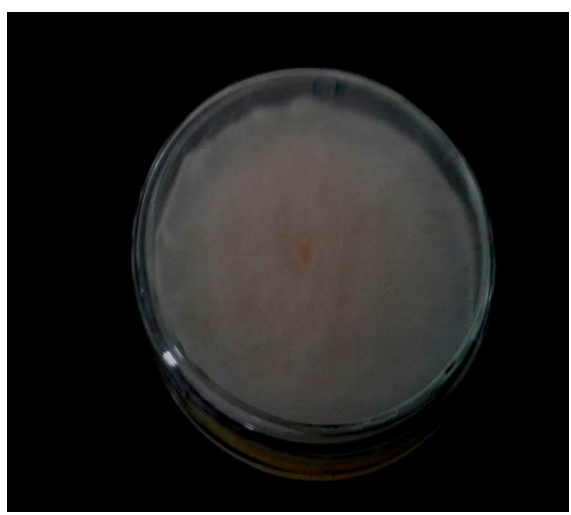

Culture filtrate

Plate 5. Purified bacteriocin and culture filtrate showing zone of inhibition against E.coli respectively

against the food pathogen $E$. coli thus confirming their antibacterial activity. Similar result was also reported by Dhanapathi et al., (2008) paving for the possibility of exploiting Bacillus subtilis for bacteriocin production to be used up as bio preservative in the food Industry.

\section{Conclusion}

Thus from the present study, it is apparent that the bacteriocin produced by Bacillus subtilis is useful in the biological control of pathogenic and food spoilage microorganisms such as E. coli. However, nearly all studies concerning food application have been focusing primarily on LAB bacteriocins, especially nisin and a few others. Eventhough nisin is the only bacteriocins currently licensed as a preservative, its applications are restricted owing to its very low activity at an alkaline or a neutral $\mathrm{pH}$. Hence, bacteriocin from Bacillus subtilis is considered to be a strong candidate as biopreservative in food due to its heat stability, wider $\mathrm{pH}$ tolerance.

\section{Future Prospects}

Continued research on bacteriocins will undoubtedly lead to our increased understanding, and the inhibitory spectrum of the antimicrobial substance has a potential application to be exploited as a much preferred biopreservative in the food industry. The prospects of future application/ commercialization of these B. subtilis associated bacteriocins, will rely on whether the commercial use will involve the use of the peptides in a (partially) purified or concentrated form. Therefore, it is essential to emphasize that it is necessary to intensify the study of bacteriocins produced by Bacillus subtilis spp to explore new avenues in the food and health care industry, as an effective natural biopreservative and also in the enhancement of functional food properties.

\section{Acknowledgement}

We would like to thank our Institution of Kongu Arts and Science College, Erode for providing the necessary facilities for this study.

\section{References}

1. Cleveland J., Montville T. J., Nes I. F., Chikindas M. L. "Bacteriocins: Safe, natural antimicrobials for food preservation”. Int J Food Microbiol. Vol. 71, p. 1-20, 2001.

2. Dhanapathi T. G., Prabhakar P., Prabhakar., "Antibacterial activity of Bacillus subtilis extraction pathogenic organism". Tamil Nadu J Veterinary and Animal Sciences. Vol. 4(4), p. 150-153, 2008.

3. Geis A., Singh J., Teuber M., "Potential of lactic Streptococcus to produce bacteriocin”. Appl Enviro Microbiol. Vol. 51, p. 105-109, 1983.

4. Karthikeyan V., Santosh S. W., "Isolation and partial characterization of bacteriocin produced from Lactobacillus plantarum". Afr J Microbiol Res. Vol. 3, p. 233-239, 2009.

5. Klaenhammer T. R., Bacteriocins of lactic acid bacteria. Biochimie. Vol. 70, pp. 337-349, 1998,

6. Rane S., Street vended Food in development word: Hazard Analysis. Indian J Microbiol, Vol. 51(1), p. 100-106, 2011.

7. Sharp R. J., Scawen M. D., Atkinson T. Fermentation and downstream processing of Bacillus. Biotechnology Handbook: Bacillus (Harwood CR, ed), Plenum Press, New York, p. 255-292, 1989.

8. Stein T., Bacillus subtilis antibiotics: Structures, syntheses and specific functions. Mol Microbiol. Vol. 56, p. 845-857, 2005. 